\title{
Bioactive Secondary Metabolite from Endophytic Aspergillus Tubenginses ASH4 Isolated from Hyoscyamus muticus: Antimicrobial, Antibiofilm, Antioxidant and Anticancer Activity
}

\author{
Heba I. Elkhouly ${ }^{1}$, Ahmed A. Hamed ${ }^{2},{ }^{*}$, Asmaa M. El Hosainy', Mosad A. Ghareeb ${ }^{3}$, Nagwa M. Sidkey ${ }^{1, *}$
}

Heba I. Elkhouly ${ }^{1}$, Ahmed A. Hamed $^{2, *}$, Asmaa M. El Hosainy', Mosad A. Ghareeb ${ }^{3}$, Nagwa M. Sidkey,**

'Botany \& Microbiology Department, Faculty of Science, Al-Azhar University (Girls Branch), Cairo, EGYPT.

${ }^{2}$ Microbial Chemistry Department, Genetic Engineering and Biotechnology Division, NRC, Dokki-Giza, EGYPT.

${ }^{3}$ Medicinal Chemistry Department, Theodor Bilharz Research Institute, Kornaish El-Nile, Imbaba, Giza, EGYPT.

\section{Correspondence}

\section{Ahmed A. Hamed}

Microbial Chemistry Department, Genetic Engineering and Biotechnology Division, NRC, Dokki-Giza, EGYPT.

E-mail: ahmedshalbio@gmail.com

\section{Nagwa M. Sidkey}

Botany \& Microbiology Department, Faculty of Science,

Al-Azhar University (Girls Branch), Cairo, EGYPT.

E-mail: nagwa.sidkey@nagwasidkey.com

History

- Submission Date: 03-11-2020;

- Review completed: 25-01-2021;

- Accepted Date: 08-02-2021.

DOI : 10.5530/pj.2021.13.55

Article Available online http://www.phcogj.com/v13/i2

Copyright

(๔) 2021 Phcogj.Com. This is an openaccess article distributed under the terms of the Creative Commons Attribution 4.0 International license.

\begin{abstract}
Background: Endophytes are the richest sources of natural compounds, showing biological varieties and pharmacological activities. Objective: This study aims to isolate bioactive secondary metabolites from endophytic Aspergillus tubenginses with study the biological activity of the isolated bioactive compounds. Materials and Methods: Anofinic acid were obtained from Aspergillus tubenginses crude extract using chromatographic techniques and characterized by spectral analysis. Results: Nine endophytic fungi were isolated from Hyoscyamus muticus plant. The most efficient isolate was AF3 identified as Aspergillus tubenginses ASH4 by $18 \mathrm{~S}$ rRNA gene sequencing. Anofinic acid is an isolated active metabolite biosynthesized by $A$. tubenginsis was extracted from ethyl acetate with UPAC name of 2,2-dimethyl-2H-1-benzopyran-6-carboxylic acid. It shows a strong antimicrobial activity against human pathogenic bacteria such as Pseudomonas aeruginosa, Staphylococcus aureus, Escherichia coli, Candida albicans and Bacillus subtilis. Moreover, anofinic acid inhibits biofilm formation and has antioxidant activity, with strong activity against some carcinoma cells such as HCT-116, Hep-G2 and MCF-7. Conclusion: Anofinic acid was purified from the endophytic Aspergillus tubenginses crude extract and showed antimicrobial, antibiofilm, antioxidant, anticancer activities.
\end{abstract}

Key words: Hyoscyamus muticus, Endophytes, Aspergillus tubenginses, Bioactive secondary metabolite.

\section{INTRODUCTION}

Scientists are tackling different diseases in our society due to rehabilitated environment and lifestyle. Several researchers are working on these emerging diseases to understand and cure them using different chemical and natural formulations. However, many areas are untouched due to poor knowledge and techniques. ${ }^{1,2}$ Researchers are trying to isolate new bioactive compounds from new species of fungal endophytes for medicinal, agricultural and industrial applications as reported by Anisworth et al. (1973); Smith et al. (2008); Garg et al. (2011); Fahmy et al. (2017); Hamed et al. (2018); Nurunnabi et al. (2020)..$^{3-8}$

Endophytic fungi have a symbiotic relationship between fungi and their host plants. ${ }^{6}$ Symbiosis refers to the living together of several species by which symbiont and host are beneficiaries. ${ }^{9-11}$ The secondary endophytic fungal metabolites have a various biological activity. The multitude of secondary metabolites derived from fungal endophytes has established therapeutic applications such as anticancer, antimicrobials, antitumor and antidiabetics, and cholesterol inhibitors and antioxidant agents. . $^{72-14}$

Wang et al. (2007) showed that, endophytic fungal metabolites can also be used effectively in weed control. For example, Cladosporium sp. created the
Brefeldin A. that suppresses the maturity of weed pollen tubes of Picea meyeri. ${ }^{15}$ Khan et al. (2012) declared that, Paraconiothyrium sp. generates ascotoxin which influences seed germination of Echinochloa crus-galli and Lactuca sativa. ${ }^{16}$ Fungal endophytes possess defensive mechanisms and greatly affect plant community growth. ${ }^{17}$ Therefore, the aim of this study was to investigate the bioactive metabolites of endophytic Aspergillus tubenginses with biological evaluation of purified secondary metabolites.

\section{EXPERIMENTAL}

\section{Collection of plant samples}

Plant samples were collected from Wadi-Elnatrun Valley, labeled, transported in icebox to the Ecology laboratory and identified by Dr. Albaraa Salaheldin, Faculty of Science, Al-Azhar University. The identified specimens were launched in the Biotechnology Lab., Faculty of Science (Girls Branch), Al-Azhar University, Cairo, Egypt.

\section{Endophytic fungal isolation}

Endophytic fungi were isolated from plant parts according to the method of Kyeremeh et al. (2017). ${ }^{18}$ To make ensure that, isolated fungi are endophytes, the plant part surfaces were sterilized by rinsing with sterile distilled water (SDW), followed by dipping in to $70 \%$ ethanol for $1 \mathrm{~min}$. the pieces were again rinsed 
in SDW, immersed in $2 \%$ sodium hypochlorite for $1 \mathrm{~min}$. followed by rinsing with SDW triply. The sterilized plant parts were allowed to dry in laminar flow, and a healthy leaf was cut into small pieces of $1 \mathrm{~cm}^{2}$ and placed on a PDA plate. To check the efficiency of surface sterilization procedure, 4-5 water drops from the final rinse were inoculated on a PDA medium, held for approximately 5-6 days to investigate the growth of any endophytic fungi. The most potent obtained fungal endophyte was identified using 18S rRNA analysis, Macrogen Company, South Korea.

\section{Genetic identification of endophytic fungus}

Here, $18 \mathrm{~S}$ rRNA analysis was performed on the endophytic fungus by biosynthesizing the major compound. In the laboratory, fungal DNA was extracted using the Qiagen DNeasy Mini Kit protocol. The extracted DNA was subjected to polymerase chain reaction using (5'-TCCGTAGGTGAACCTGCG-3')/ITS4 (5'-TCCTCCGCTTATTGATATGC-3') universal primers. In Macrogen Companies, Seoul, South Korea. Amplified DNA was subjected to DNA sequencing and the gained DNA sequence was parallel to the DNA sequence presented at NCBI GenBank *. The resulting gene sequence was submitted to the NCBI GenBank database and an accession number was attained. http://www.ncbi.nlm.nih.gov.blast

\section{Production of bioactive compounds}

Rice in the solid state was used as a fermentation media, 100g rice was soaked in $100 \mathrm{~mL}$ distilled sea water (Mediterranean Sea), and autoclaved, and $1 \mathrm{ml}$ of endophytic fungus was introduced to each medium flask. The inoculated flasks were incubated under static conditions at $30^{\circ} \mathrm{C}$ for 15 days. The extraction was performed using ethyl acetate, and then the organic phase was gathered, stored, and dried at $37^{\circ} \mathrm{C}{ }^{19-21}$

\section{Antimicrobial activity}

The antimicrobial activity of the obtained crude extracts was performed using agar diffusion method according to Abdel-Aziz et al. (2019). ${ }^{22}$ Each fungal crude extract was dissolved in $\mathrm{MeOH}$ at $500 \mu \mathrm{g} / \mathrm{ml}$ and Aliquots of $50 \mu \mathrm{l}$ were loaded on disks (Whattman No. 1 filter paper, $5 \mathrm{~mm}$ ). The inhibition zone diameter was measured against various of pathogenic microorganisms comprising: Gram+ve bacteria; (Staphylococcus aureus ATCC6538-P) and Bacillus subtilis. Gram-ve bacteria (Pseudomonas aeruginosa ATCC27853) and E. coli. and Yeasts (Candida albicans ATCC10231). On the other hand, the antibacterial activity of the pure compound isolated from selected fungus was measured using Antimicrobial assay and MIC were performed as described by Ingebrigtsen et al. (2016). ${ }^{23}$

All test microbes were obtained from the Culture Collection Center (Microbial Chemistry Department and National Research Center, NRC), Egypt.

\section{Antibiofilm activity}

MTP assays were conducted to test antibiofilm activity of the fungal crude extracts and pure compound. The test was performed using 96 well-flat bottom polystyrene titer plates and four clinical microbes were also used (P. aeruginosa, S. aureus, E. coli, and B. subtilis) according to Christensen et al. (1985) ${ }^{24}$ and Hamed et al. (2020). ${ }^{25}$ The optical density was determined at $570 \mathrm{~nm}$ using a spectrostar nanomicroplate reader (BMG LABTECH GmbH, Allmendgrun, Germany).

\section{Determination of total antioxidant capacity (TAC) and} total phenolic content (TPC)

The antioxidant activity of the ethyl acetate crude extracts along with pure compound was determined by phosphor molybdenum assay according to Ghareeb et al. $(2014 \& 2016)^{26,27}$ and Saad et al. $(2017)^{28}$. The antioxidant activity was conducted as the number of ascorbic acid equivalent (AAE), in triplicate. The total phenolic content of fungal endophytic ethyl acetate extract was also estimated using phosphomolybdenum assay according to Shoeb et al. (2014). ${ }^{29}$

\section{Extraction, purification and structure elucidation}

Purification started by fractionation using liquid-liquid partitioning according to the Kupchan original protocol. ${ }^{30}$ The extraction procedures mainly depend on the polarity of interest compounds (which can be determined by thin layer chromatography with varying polarity eluents or by analytical HPLC. The most potent fraction was further purified using Size-exclusion chromatography technique via using Sephadex LH-20. The separation was based on molecular weight. The purified compound was subjected to NMR spectroscopy for structure elucidation as well as Thermo Scientific LTQ Orbitrap XL Mass Spectrometer for molecular formula identification.

\section{Anticancer activity}

Four different cell lines were used, human lung fibroblast normal cell line (WI-38), colorectal carcinoma colon cancer (HCT-116), breast cancer of the mammary gland (MCF- 7), and hepatocellular cancer (Hep-G2). The cell lines were obtained from American Type Culture Collection (ATCC), through Biological Products and Vaccine Holding Company (VACSERA), Cairo, Egypt. In reference, doxorubicin has been used as a traditional anticancer drug.

Using the MTT test, the abovementioned cell lines were employed to assess the inhibitory effects on cell growth of pure compounds extracted from endophytic fungus. The colorimetric assay depends on the conversion of yellow tetrazolium bromide (MTT) in viable cells into a violet formazan derivative by mitochondrial succinate dehydrogenase in viable cells. The cell lines were cultivated using 10 $\%$ fetal bovine serum in the RPMI-1640 medium. Antibiotics added in a $5 \% \mathrm{CO}_{2}$ incubator were $100 \mathrm{units} / \mathrm{ml}$ of penicillin and $100 \mu \mathrm{g} / \mathrm{ml}$ of streptomycin at $37^{\circ} \mathrm{C}$. The cell lines were seeded for $48 \mathrm{~h}$ under 5 percent $\mathrm{CO}_{2}$ in a 96 -well plate at a density of $1.0 \times 10^{4}$ cells/well at $37^{\circ} \mathrm{C}$. The cells were treated with different concentrations of compounds after incubation for $24 \mathrm{~h}$. A $20 \mu \mathrm{l}$ of MTT solution at $5 \mathrm{mg} / \mathrm{ml}$ was used in the drug treatment, added and incubated for $4 \mathrm{~h}$, and $100 \mu \mathrm{l}$ of DMSO was added to dissolve the purple formazan formed in each well. The colorimetric assay was recorded at $570 \mathrm{~nm}$ using a plate reader (EXL 800 , USA). The relative cell viability in percentage was calculated as (A570 of treated samples/A570 of untreated sample) x 100. ${ }^{32,33}$

\section{RESULT AND DISCUSSION}

\section{Sample collection and isolation of endophytes}

The plant sample was gathered from Wadi-Elnatrun Valley, Egypt. The plant was identified based on the morphological features as Hyoscyamus muticus L. Ten endophytic fungi were isolated from Hyoscyamus muticus L, coded and kept at microbial culture collection, Microbial Chemistry Department, Dokki, Giza, Egypt.

El-Zayat et al. (2008) isolated 18 fungi from the surface of $H$. muticus plant. ${ }^{34}$ Three species have only been isolated as endophytic fungi from the medicinal plant Hyoscyamus muticus L. Abdel-Motaal et al. (2010) isolated 44 endophytes and they opserved that, A. fumigatus is the most common species obtained from all plant tissues at different habitats. ${ }^{35}$ Sharma et al. (2016) isolated endophytic fungus Pestalotiopsis neglecta from medicinal plant leaves (Cupressus torulosa). which could be a potential source for bioactive compound. ${ }^{36}$ 


\section{Evaluation of the antimicrobial activities of fungal endophytes}

The crude extracts from the isolated 10 endophytic fungi were prepared by cultivation of the 10 fungal isolates on rice medium followed by ethyl acetate extraction. The antimicrobial activity of the crude extracts was evaluated (in vitro) against several test pathogenic microorganisms comprising 2 Gram -ve, 2 Gram +ve bacteria and one yeast. Results showed that, nearly $70 \%$ of the endophytic fungi isolated from $H$. muticus L exhibited antibacterial activities. The most promising endophytic fungi from $H$. muticus $L$ plant were AF3, 15F6, 15F8, 15F13 and 15F14 with inhibition zone 17-21, 15-17, 14.5-19.2, 14.5-17, and 7-14 $\mathrm{mm}$, respectively, as recorded in Table 1.

Similarly, El-Said et al. (2016) showed that, Aspergillus versicolor, A. flavus, Eurotium chevalieri, Cordella clarkia, P. funicolusum and Penicillium aurantiogriseum were the most active fungi isolated from H. muticus plant with inhibition zone ranging from $8-16 \mathrm{~mm} .^{37}$

Another study by Basheer et al. (2018) showed that, Aspergillus terreus isolated from Avicennia marina (South Safaga) has antimicrobial efficacy against Klebsiella pneumoniae, Staphylococcus aureus, Bacillus subtilis, Proteus vulgaris, as well as Streptococcus pyogenes with inhibition zone ranging from $16-21 \mathrm{~mm}$ and lacks fungal activity against $C$. albicans P. chrysogenum and A. niger. ${ }^{38}$ while, endophyte Aspergillus fumigatus isolated from the same plant lacks microbial activity. A. fumigatus isolates from $H$. muticus were the most active isolates versus Klebsiella pneumoniae and Staphylococcus aureus according to Gherbawy et al. (2016). ${ }^{39}$

Observably, different endophytic fungal extracts from the same plant display various antimicrobial activities Table (1). These sensitivity differences could be attributed to the isolate species, level, nature, and mode of action of antimicrobial agents existing in their extracts and on various trial microorganisms as reported by Barbour et al. $(2004)^{40}$. In this study, the most potent endophytic isolates (AF3, 15F6, 15F8, $15 \mathrm{~F} 13$, and $15 \mathrm{~F} 14)$ were selected for other screening methods and investigations.

\section{Antioxidant capacity of endophytic fungal extract using phosphomolybdenum assay}

Phosphomolybdenum assay is based on $\mathrm{Mo}^{4}$ reduction to $\mathrm{Mo}^{+5}$ through interaction with the tested sample and sequent formation of a green color $\left[\right.$ phosphate $=\mathrm{Mo}^{+5}$ complex with maximum absorption of $695 \mathrm{~nm}$ in the acidic medium. ${ }^{41,42}$. Results showed that, TAC values for the tested crude endophyte extracts ranged from $111.66-880.66 \mathrm{mg}$ $\mathrm{AAE} / \mathrm{g}$ dry extract. The results are in the order: $15 \mathrm{~F} 13>15 \mathrm{~F} 8>\mathrm{AF} 3>$ $15 \mathrm{~F} 6>15 \mathrm{~F} 14$ as presented in Table 2 .

Rudgers et al. (2007) stated that plant phenolic compounds influenced the community of endophytes. ${ }^{43}$ Therefore, the higher the content of active compounds in host plant, the more richness with endophytic microorganisms. Previous reports revealed that endophyte extracts and their derived pure isolates exhibit noticeable antioxidant potentials. ${ }^{44,45}$.

Antibiofilm activity of endophytic extract of fungal isolates against some pathogenic microorganisms

The evaporated ethyl acetate extract was diluted with methanol for MTP test that was performed according to Christensen et al. (1985). ${ }^{24}$ From the extracts, a concentration $(100 \mu \mathrm{g} / \mathrm{mL})$ was selected for biofilm inhibition assay against tested pathogens and their virulence factor in terms of biofilm formation. The test was performed in a 69-well microtiter plate. The crude extract from fungal endophyte AF3 showed better inhibition percentage in $(100 \mu \mathrm{g} / \mathrm{mL})$ with $50.06 \%$ against Bacillus subtilis, $37.68 \%$ against $E$ coli, $28.44 \%$ against $P$ seudomonas aeruginosa and $60.8 \%$ against Staphylococcus aureus Figure 1 . The results showed that the crude compound of AF3 was the most active against biofilm colonization and cell adherence

In view of the findings of Martin-Rodriguez et al. (2014), marine endophyte extracts (Khuskia sp., Fusarium sp., Sarocladium sp., also Epicoccum sp.) possess perfect biofilm inhibition percentage. ${ }^{46}$

Rajivgandhi et al. (2018) reported that, crude compound $(100 \mu \mathrm{g} / \mathrm{mL})$ isolated from endophytic actinomycetes demonstrated antibiofilm

Table 1: In vitro antimicrobial activity of the isolated endophytic fungi against some pathogenic microorganisms.

\begin{tabular}{|c|c|c|c|c|c|c|c|c|c|c|c|}
\hline $\begin{array}{c}\text { Fungal } \\
\text { isolates } \\
\text { Pathogens }\end{array}$ & $15 F 1$ & $15 \mathrm{~F} 2$ & $15 \mathrm{~F} 3$ & $15 F 4$ & $15 \mathrm{~F} 6$ & $15 \mathrm{~F} 8$ & $15 \mathrm{~F} 11$ & $15 \mathrm{~F} 13$ & $15 F 14$ & AF3 & Standard \\
\hline Yeast & \multicolumn{10}{|c|}{ Mean diameter $(\mathrm{mm}) \pm \mathrm{SD}$} & Amphotorcin \\
\hline C. albicans & $0 \pm 00$ & $0 \pm 00$ & $0 \pm 00$ & $0 \pm 00$ & $16 \pm 0.15$ & $19.2 \pm 0.03$ & $0.6 \pm 002$ & $17 \pm 0.02$ & $15 \pm 0.01$ & $21 \pm 0.01$ & $20 \pm 002$ \\
\hline Gram +ve bacteria & & & & & & & & & & & Vancomycin \\
\hline S.aureus & $0 \pm 00$ & $0 \pm 00$ & $0 \pm 00$ & $0 \pm 00$ & $16 \pm 0.02$ & $15 \pm 0.14$ & $0 \pm 00$ & $15 \pm 0.05$ & $14 \pm 0.02$ & $18 \pm 0.02$ & $20 \pm 031$ \\
\hline & & & & & & & & & & & Ampicillin \\
\hline B. subtilis & $0 \pm 00$ & $0 \pm 00$ & $0 \pm 00$ & $0 \pm 00$ & $15 \pm 0.05$ & $17 \pm 0.25$ & $6.5 \pm 0.02$ & $16 \pm 0.12$ & $8 \pm 0.12$ & $19 \pm 0.12$ & $21 \pm 0.05$ \\
\hline Gram -ve bacteria & & & & & & & & & & & Gentamicin \\
\hline P. aeruginosa & $0 \pm 00$ & $0 \pm 00$ & $0 \pm 00$ & $0 \pm 00$ & $17 \pm 0.03$ & $14.5 \pm 0.03$ & $6 \pm 0.02$ & $14.5 \pm 0.02$ & $11 \pm 0.08$ & $17 \pm 0.12$ & $20 \pm 0.05$ \\
\hline E. coli & $0 \pm 00$ & $0 \pm 00$ & $0 \pm 00$ & $0 \pm 00$ & $16 \pm 0.18$ & $15 \pm 0.15$ & $0 \pm 00$ & $15 \pm 0.1$ & $7 \pm 0.1$ & $17 \pm 0.14$ & $20 \pm 0.15$ \\
\hline
\end{tabular}

Table 2: Antioxidant capacity (TAC) of crude endophyte extracts.

\begin{tabular}{cc}
\hline Isolate code & $\begin{array}{c}\text { Total antioxidant capacity (mg AAE/g dry extract) } \\
\text { means } \pm \text { S. D }\end{array}$ \\
\hline $15 \mathrm{~F} 6$ & $185.0 \pm 6.0$ \\
$15 \mathrm{~F} 8$ & $846.66 \pm 5.23$ \\
$15 \mathrm{~F} 13$ & $880.66 \pm 8.82$ \\
$15 \mathrm{~F} 14$ & $111.66 \pm 7.57$ \\
$\mathrm{AF} 3$ & $753.33 \pm 6.17$ \\
\hline
\end{tabular}

AAE: Ascorbic acid equivalent. 

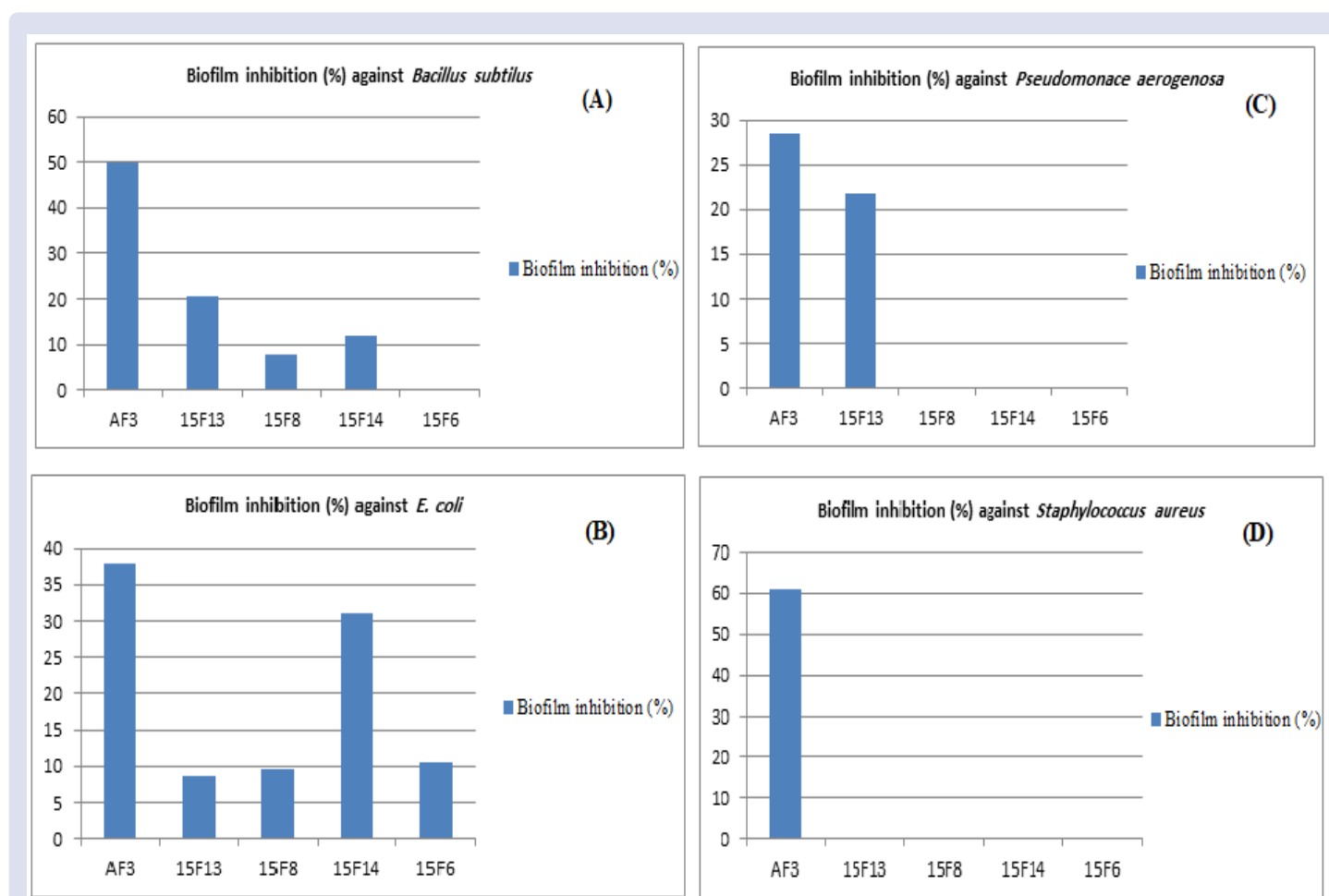

Figure 1: Biofilm inhibition (\%) by different endophytic extracts of fungal isolates against some microbial strains.

activity with $82 \%$ and $77 \%$ inhibition against bacterial films of both Pseudomonas aeruginosa and Klebsiella pneumoniae, respectively. ${ }^{47}$ Meenambiga and Rajagopal (2018) reported that, the majority of solvent extracts reported possess strong inhibitory effect on biofilm formed by C. Albicans on chloroform extract with elevated activity. ${ }^{48}$ The reduction percentage of biofilm inhibition were $74.86 \%$ and $72.53 \%$ respectively, for chloroform and ethyl acetate, and $60.61 \%$ and $52.60 \%$ for hexane and methanol extracts.

\section{Molecular identification the most active endophytic fungal isolate}

The $18 \mathrm{~S}$ rRNA gene sequence was used to identify and oppose other identified sequences available in the GeneBank database using BLAST to indicate the score similaritie sand calculate the statistically significant differences of matches (http://www.blast.ncbi.nlm.nih.gov/Blast). The results established a very close similarity with Aspergillus tubenginses using the $18 \mathrm{~S}$ rRNA gene sequence with $100 \%$ homology of the isolate AF3. The phylogenetic analysis and tree were composed using the neighboring method (Figure 2) by MEGA 7 program according to Kumar et al. (2016). ${ }^{49}$ Based on the analysis of the DNA sequence and morphological characteristics of the AF3 isolate (Supplementary 1), the isolated strain was identified as Aspergillus tubenginses ASH4 and deposited in GenBank with the accession no. MN784618.1.

\section{Extraction and Bio-guided fractionation and purification}

Large scale fermentation of the most potent endophytic fungus Aspergillus tubenginses ASH4 was carried out on rice medium, incubated for 15 days, extracted by ethyl acetate and evaporated using a rotary evaporator at $40^{\circ} \mathrm{C}$. Purification was started by fractionation using liquid-liquid partitioning according to the method of Kupchan original protocol. ${ }^{30}$ Five aqueous fractions: methanol, $n$-hexane, $n$-butanol, dichloromethane (DCM) and water were performed as shown in Figure 3. Antimicrobial screening indicated that only dichloromethane (DCM) followed by n-hexane extracts for Aspergillus tubenginses ASH4 exhibited antimicrobial activity against the tested pathogenic microorganisms.

Conversely, antioxidant evaluation of the five fractions, showed that butanol and methanol extracts of Aspergillus tubenginses ASH4 exhibited high antioxidant activity. Also, the results revealed various total phenolic concentrations of ethyl acetate fractions in endophytic fungal extracts as manifest in Table 3. The estimation varied from 48.0 $-134.62 \mathrm{mg}$ gallic acid equivalent (GAE)/g of dry weight. The highest concentration of phenols was observed in extract of ASH4 $\mathrm{BuOH}$ (134.62 mg GAE/g extract). Considering findings of other studies, the polyphenolic-rich extracts could loss an electron through their redox reaction with a molybdotungstate reagent (Folin Ciocalteu's reagent). This electron transfer reaction induces a blue color, which can be quantified simply by spectrophotometry at $765 \mathrm{~nm} .{ }^{42}$ Also, based on the antimicrobial screening (Table 4), the fraction dichloromethane (DCM) was active, and therefore was selected for further processing using different chromatographic techniques. Compound (1) was identified as anofinic acid (2,2-dimethyl-2H-1-benzopyran-6-carboxylic acid).

Anofinic acid (Figure 3) was isolated as a yellow fine crystal from the DCM fraction using Sephadex LH-20 subcolumn eluted with a gradient mix elution system using aqueous methanol. It showed a molecular formula $\left(\mathrm{C}_{12} \mathrm{H}_{12} \mathrm{O}_{3}\right)$ and molecular weight of 204.22 (Supplementary 1). In ${ }^{1} \mathrm{H}$-NMR spectrum, it showed characteristic signals in the aromatic region between $\delta_{\mathrm{H}} 6.95$ to $\delta_{\mathrm{H}} 7.45 \mathrm{ppm}$, resonating methyl protons appeared at $\delta_{\mathrm{H}} 1.5 \mathrm{ppm}$. Two olefinic protons were resonated at $\delta_{\mathrm{H}}$ 6.33 and $5.77 \mathrm{ppm}$. The hydroxyl proton of the carboxylic group was resonated at $\delta_{\mathrm{H}} 11.69 \mathrm{ppm}^{31}$

\section{Evaluation of bioactivity of pure compound antibacterial activity}

Data illustrated in Figure 5 represent the antimicrobial activity of the pure compound from Aspergillus tubenginses ASH4 against a set of microorganisms comprising Gram-ve bacteria and Gram+ve bacteria (P. aeruginosa, S. aureus, B. subtilis and E. coli). The results revealed that 


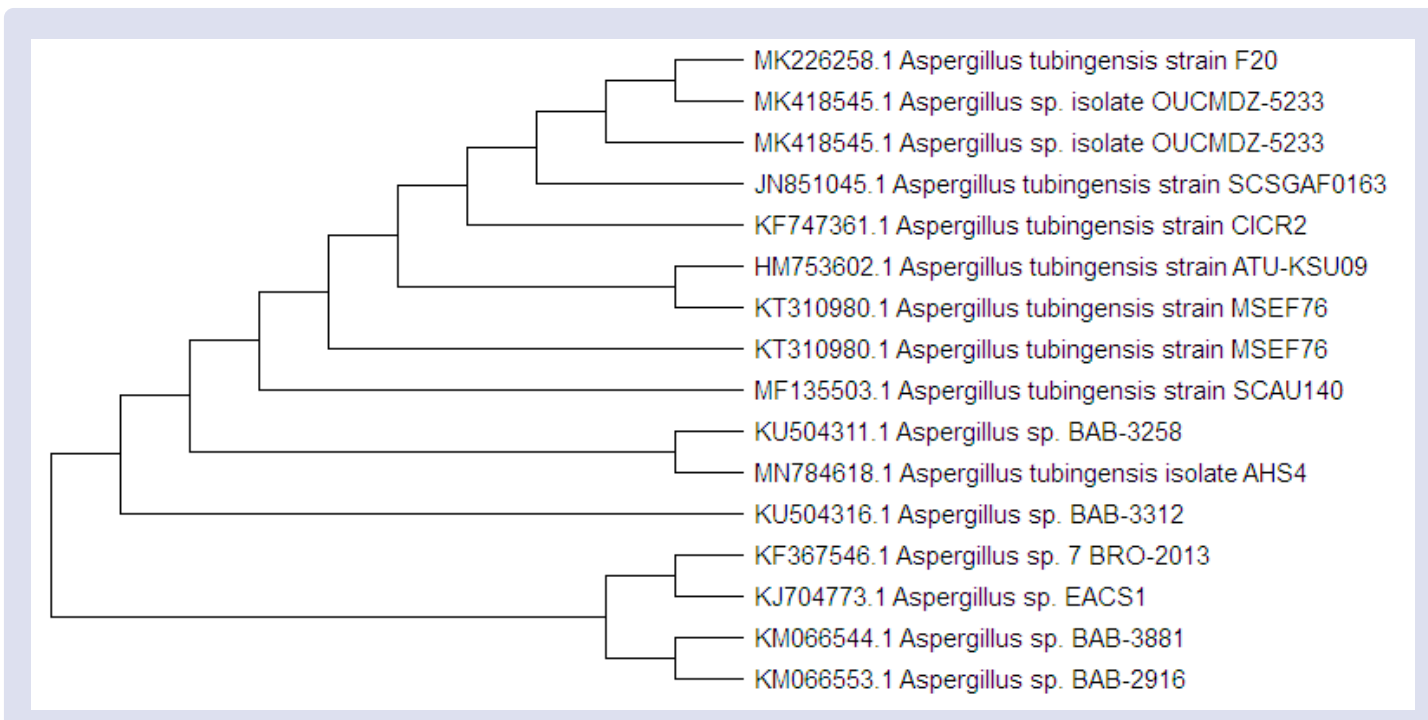

Figure 2: Constructed phylogentic tree of Aspergillus tubenginses. ASH4.

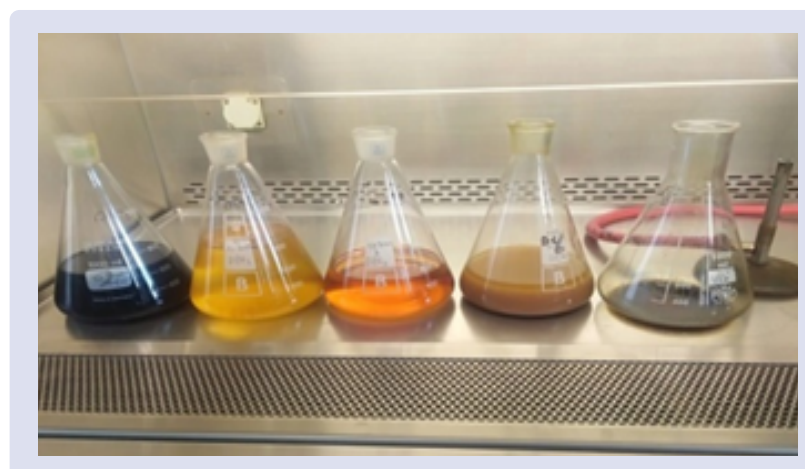

Figure 3: Five extracts from left to right; aqueous methanol, $\mathrm{n}$-butanol, hexane, DCM and water.

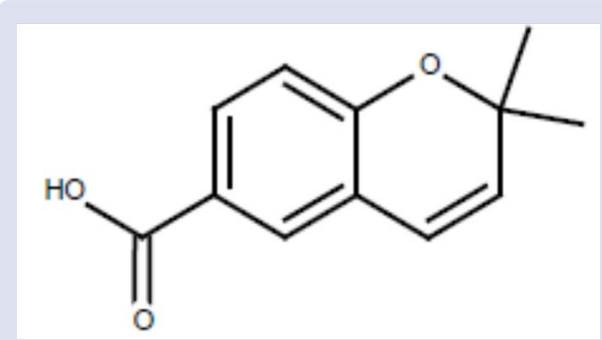

Figure 4: Anofinic acid structure.

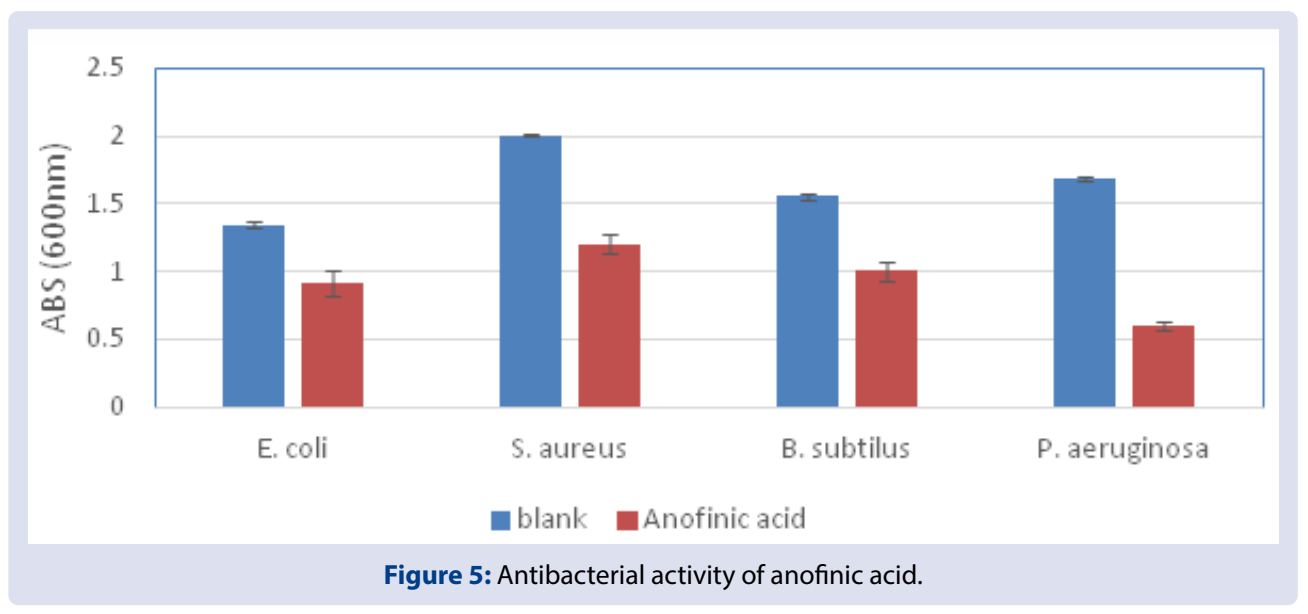


anofinic acid exhibited antibacterial activity against all tested bacteria.

Recently, the introduction of new pathogens, such as SARS, H1N1 and different forms of influenza, has become a significant public health threat. Most of these emerged diseases are occasioned by microorganisms and occasional microbes become increasingly drug resistant with time. ${ }^{50}$ To overcome such infectious diseases, novel microorganism and plant bioactive compounds may stand by the best substitutional provenance of potential medicines. ${ }^{51}$ Since, plant is the prime source of bioactive compounds, endophytes may nevertheless compete a vital role in the quest for novel compounds of biological activity. ${ }^{52}$

\section{Antibiofilm activity of pure compound}

Using microtiter biofilm plate assay, the biofilm inhibition activity of the pure compound of Aspergillus tubenginses ASH4 was measured against four clinical pathogenic bacteria (P. aeruginosa, S. aureus, E. coli and $B$. subtilis), and the results were compared with untreated biofilms (control) for each pathogen (Table 5).

\section{TAC}

The results presented in Table 6 show that the TAC of pure anofinic acid is $409.92 \mathrm{mg} \mathrm{AAE} / \mathrm{g}$ compound. Ghareeb et al. (2019b $)^{45}$ evaluated the TAC of the pure compounds isolated from terrestrial fungus Penicillium sp. SAM16-EGY, in which TAC values ranged from $332.16-608.59 \mathrm{mg}$ AAE/g compound.

\section{Anticancer activity}

This study revealed that, for pure compound (anofinic acid), $\mathrm{IC}_{50}$ value of $28.14 \mu \mathrm{g} /$ well was recognized against the colon carcinoma cells, $\mathrm{IC}_{50}$ value of $31.65 \mu \mathrm{g} /$ well for hepatocellular carcinoma, and $\mathrm{IC}_{50}$ value of $22.61 \mu \mathrm{g} /$ well for breast carcinoma. Also, for crude fungal extract $\mathrm{IC}_{50}$ value of $9.18 \mu \mathrm{g} /$ well for colon, $\mathrm{IC}_{50} 19.37 \mu \mathrm{g} /$ well against hepatocellular carcinoma and $\mathrm{IC}_{50} 5.89 \mu \mathrm{g} /$ well against breast carcinoma (Table 7). The results indicated that the crude extracted from Aspergillus tubengensis, ASH4 shows significant strong antiproliferative activity against colon, hepatocellular and breast carcinoma cell line as compared with control (DOX). Also, anofinic acid showed moderate antiproliferative activity

Table 3: Antioxidant capacity and total phenolic content of Aspergillus tubenginses ASH4 different fractions.

\begin{tabular}{ccc}
\hline Fraction & Total antioxidant capacity $(\mathrm{mg} \mathrm{AAE} / \mathrm{g}$ extract) means \pm S.D & Total phenolic content (mg GAE/g extract) means \pm S.D. \\
\hline ASH4Methanol & $270.66 \pm 5.77$ & $102.56 \pm 4.16$ \\
ASH4 Hexane & $53.34 \pm 5.03$ & $48.0 \pm 4.32$ \\
ASH4 DCM & $189.56 \pm 6.11$ & $89.47 \pm 3.29$ \\
ASH4 But. & $324.39 \pm 4.61$ & $134.62 \pm 3.89$ \\
ASH4 H2O & $124.78 \pm 3.05$ & $68.57 \pm 4.24$ \\
\hline
\end{tabular}

AAE: Ascorbic acid equivalent, GAE: Gallic acid equivalent

Table 4: Antimicrobial activity of Aspergillus tubenginses ASH4 different fractions against some pathogenic microorganisms.

\begin{tabular}{|c|c|c|c|c|c|}
\hline \multirow{2}{*}{ Fractions } & \multicolumn{5}{|c|}{ Zone of inhibition (mm) } \\
\hline & P. aeruginosa & S. aureus & E. coli & B. subtilis & C. albicans \\
\hline ASH4 $\mathrm{MeOH}$ & 10 & 11 & - & - & 13 \\
\hline $\mathrm{ASH} 4 \mathrm{H}_{2} \mathrm{O}$ & - & - & - & - & 07 \\
\hline ASH4 DCM & 14 & 15 & 16 & 13 & 15 \\
\hline ASH4 BuOH & - & - & - & - & - \\
\hline ASH4 Hexane & - & - & 13 & 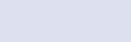 & 14 \\
\hline Control & 20 & 20 & 20 & & 20 \\
\hline
\end{tabular}

Table 5: Biofilm inhibition (\%) of pure compound against pathogenic bacteria.

\begin{tabular}{cccccc}
\hline \multirow{2}{*}{ Pure compound } & \multicolumn{3}{c}{ Anti-biofilm formation (\%) } \\
\cline { 2 - 6 } & E. coli & S. aureus & B. subtilis & P. aeruginosa \\
\hline Anofinic acid & & $34.45 \pm 3.02$ & $61.39 \pm 6.02$ & $54.93 \pm 8.02$ \\
\hline
\end{tabular}

Table 6: Antioxidant capacity (TAC) of the pure anofinic acid.

\begin{tabular}{|c|c|c|c|c|}
\hline Compound & \multicolumn{4}{|c|}{ Total antioxidant capacity (mg AAE/g compound) means \pm S.D. } \\
\hline Anofinic acid & \multicolumn{4}{|c|}{$409.92 \pm 3.14$} \\
\hline \multicolumn{5}{|c|}{ AAE: Ascorbic acid equivalent. } \\
\hline \multirow{2}{*}{ Comp. } & & \multicolumn{3}{|c|}{ Cytotoxicity $\mathrm{IC}_{50}(\mu \mathrm{g} / \mathrm{ml})$} \\
\hline & WI-35 & HCT-116 & Hep-G2 & MCF-7 \\
\hline DOX (control) & $6.72 \pm 0.5$ & $5.23 \pm 0.3$ & $4.50 \pm 0.2$ & $4.17 \pm 0.2$ \\
\hline AF3 crude & $29.01 \pm 0.1$ & $9.18 \pm 0.8$ & $10.41 \pm 0.9$ & $5.89 \pm 0.4$ \\
\hline Anofinic acid & $66.24 \pm 3.5$ & $28.18 \pm 2.3$ & $31.65 \pm 2.6$ & $22.61 \pm 1.8$ \\
\hline
\end{tabular}

$\mathrm{IC}_{50}(\mu \mathrm{g} / \mathrm{ml})$ : 1-10 (very strong). 11-20 (strong). 21-50 (moderate). 51-100 (week), and above 100 (no cytotoxic), DOX: Doxorubicin 
against examined cell lines cancer of the colorectal colon (HCT-116), breast cancer of the mammary gland (MCF-7), and (Hep-G2).

Extraction of natural bioactive compounds and screening them for pharmacological advantages provide a path for identifying of drug nominee as reported by Salvador-Reyes and Luesch $(2015)^{53}$ and Hamed et al. $(2020)^{25}$. Many endophytes have been described and documented to generate new compounds are successful in anticancer inspection. ${ }^{44,55}$

In another study, endophyte isolate Aspergillus sp. was led to manufacture utmost yield of $100 \mu \mathrm{g} / \mathrm{g}$ of mycelia dry weight. ${ }^{56}$ Also, Budhiraja et al. (2013) isolated Aspergillus sp. from Gloriosa superba. ${ }^{57}$ A new compound colchatetralene was isolated along with three known compounds namely ergosterol, 4-hydroxy-phthalic acid-dimethyl ester and 5-(hydroxymethyl) furan-2 carbaldehyde which was tested for cytotoxic effect on seven cell lines. Colchatetralene was found to be influential against THP-1 and MCF-7 with $\mathrm{IC}_{50}$ values of 30 and $50 \mu \mathrm{g} /$ $\mathrm{mL}$, respectively. Moreover, Lee et al. (2010) outline scarce compounds from Aspergillus versicolor isolated from Petrosia sp had $\mathrm{IC}_{50}$ opposed to HCT-15 colon cancer cell line less than $30 \mu \mathrm{g} / \mathrm{mL} .^{58}$

\section{CONCLUSION}

In this study, 10 endophytic fungal strains were isolated from Hyoscyamus muticus plant, biological screening including antibacterial, antibiofilm, and antioxidant activities of 10 fungal ethyl acetate extracts, showed that, Aspergillus tubenginses ASH4 exhibited maximum antibacterial activity against tested pathogenic strains with inhibition zone of $21 \mathrm{~mm}$, and the TAC values for the tested crude extract of Aspergillus tubenginses ASH4 was $753.33 \mathrm{mg} \mathrm{AAE} / \mathrm{g}$ dry extract. Moreover, the isolated pure compound anofinic acid inhibited biofilm formation up to $69.51 \%$. Moreover, the antioxidant activity of anofinic acid was $409.92 \mathrm{mg} \mathrm{AAE} / \mathrm{g}$. The $\mathrm{IC}_{50}$ values of anofinic acid against some carcinoma cells such as HCT-116, Hep-G2 and MCF-7 were $728.14,31.65$, and $22.61 \mu \mathrm{g} /$ well, respectively, described as very strong activities.

\section{ACKNOWLEDGEMENTS}

The authors are deeply thankful to Prof. Rainer Ebel, College of Physical Sciences, University of Aberdeen, for his support and lab facilities (MS and NMR measurements). A. A. Hamed thanks the STDF - Sience and Technology Development Fund, project No. 27701 for funding.

\section{CONFLICTS OF INTEREST}

The authors declare that they have no conflicts of interest.

\section{REFERENCES}

1. Bode $B$, Bethe $B$, Hofs $R$, Zeek $A$. Big effects from small changes: possible ways to explore nature's chemical diversity. Biochem. 2002; 3: 619-627.

2. Aditi M, Arjun V, Gayathri M. A brief review on medicinal plants from South India, endophytes and their antidiabetes properties. International Journal of Current Research. 2017; 9: 1-4.

3. Anisworth C, Sparrow K, Sussaan S. The Fungi. Advanced Treaties, Taxonomic review with keys. 1973; Academic Press, New York, USA.

4. Smith S, Tank D, Boulanger A, Bascom-Slack C, Eisenman K, David Kingery D, Babbs B, Fenn K, Greene J, Hann B, Keehner J, KelleySwift E, Kembaiyan V, Lee J, Li P, Light D, Lin H, Ma C. Bioactive endophytes warrant intensified exploration and conservation. Canadian Journal of Botany. 2008; 66:45-54.

5. Boulis AG, Hamed AA, El-Awady ME, Mohamed AR, Eliwa EM, Mohsen MS Asker MMS, Shaaban M. Diverse bioactive metabolites from Penicillium sp. MMA derived from the red sea: structure identification and biological activity studies. Archives of Microbiology. 2020; 202: 1985-1996.
6. Fahmy D, AL-Khawaja M, Zaid D, Sidkey N. Isolation and screening of endophytic microorganisms isolated from leaves of three medicinal plants growing in Marsa Matrouh. International Journal of Scientific and Engineering Research (IJSR) .2017; 6: 1858-1861.

7. Hamed AA, Abdel-Aziz MS, Abd El Hady FK. Antimicrobial and antioxidant activities of different extracts from Aspergillus unguis SPMD-EGY grown on different media. Bulletin of the National Research Centre, 2018; 29.

8. Nurunnabi TR, Sabrin F, Sharif DI, Nahar L, Sohrab MdH, Sarker SD, Rahman SMM, Billah MM. Antimicrobial activity of endophytic fung isolated from the mangrove plant Sonneratia apetala (Buch.-Ham) from the Sundarbans mangrove forest. Adv Tradit Med (ADTM). 2020;

9. Akhtar MS, Panwar J, Abdullah SNA, SiddiquiY, Swamy MK, Ashkani S Biocontrol of plant parasitic nematodes by fungi: efficacy and contro strategies. In: Meghvansi MK, Varma A (eds) Organic amendments and soil supper ssiveness in plant disease management. Springer, Geneva, pp 2015; 219-247.

10. Swamy MK, Akhtar MS, Sinniah UR. Root exudates and their molecular interactions with rhizospheric microbes. In: Hakeem KR, Akhtar MS (eds) Plant, soil and microbes, vol 2. Springer International Publishing, Geneva. 2016.

11. Hamed AA, Soldatou S, Qader MM, Arjunan S, Miranda K J, Casolari F, Pavesi C, Diyaolu OA, Thissera B, Eshelli M, Belbahri L, Luptakova L, Ibrahim, NA, Abdel-Aziz MS, Eid BM, Ghareeb MA, Rateb ME, Ebel R. Screening Fungal Endophytes Derived from Under-Explored Egyptian Marine Habitats for Antimicrobial and Antioxidant Properties in Factionalised Textiles. Microorganisms. 2020; 8: 1617.

12. Strobel GA. Endophytes as source of bioactive products. Microbes and Infection .2003; 5: 535-544.

13. Eskander DM, Atalla SMM, Hamed AA, El-Khrisy EDA. Investigation of Secondary Metabolites and its Bioactivity from Sarocladium kiliense SDA20 Using Shrimp Shell Wastes. Pharmacognosy Journal. 2020; 12; 636-644.

14. Abdel-Aziz MS, Ghareeb MA, Saad AM, Refahy LA and Hamed AA Chromatographic isolation and structural elucidation of secondary metabolites from the soil-inhabiting fungus Aspergillus fumigatus 3T-EGY. Acta Chromatographica, 2018; 243-249

15. Wang FW, Jiao RH, Cheng AB, Tan SH, Song YC. Antimicrobial potentials of endophytic fungi residing in Quercus variabilis and brefeldin A obtained from Cladosporium sp. World Journal of Microbiology and Biotechnology. 2007; 23: 79-83.

16. Khan AL, Muhammad H, Javid H, Sang-Mo K, In-Jung L. The newly isolated endophytic fungus Paraconiothyrium sp. LK1 produces Ascotoxin. Molecules .2012; 17:1103-1112.

17. Park SH, Eom AH. Effects of mycorrhizal and endophytic fungi on plant community: a Microcosm Study. Mycobiology.2007;35: 186190.

18. Kyeremeh K, Owusu KB, Ofosuhene M, Ohashi M, Agyapong J. Anti-Proliferative and Anti-Plasmodia Activity of Quinolactacin A2, Citrinadin A and Butrecitrinadin co-isolated from a Ghanaian Mangrove Endophytic Fungus Cladosporium oxysporum strain BRS2A-AR2F. J Chem Applications. 2017;3: 12.

19. Hifnawy MS.; Hassan HM, Mohammed R, Fouda MM, Sayed AM Hamed AA, AbouZid SF, Rateb ME, Alhadrami HA, Abdelmohsen UR. Induction of Antibacterial Metabolites by Co-Cultivation of Two RedSea-Sponge-Associated Actinomycetes Micromonospora sp. UR56 and Actinokinespora sp. EG49. Mar. Drugs. 2020; 18:243.

20. Mane R, Shinde M, Wagh P, Malkar H. Isolation of Endophytic microorganisms as a source of novel secondary metabolite producers against Tuberculosis. International Journal of Science and Research Technology. 2017; 3, 1267-1269.

21. Soldatou S, Qader MM, Pavesi C, Miranda KJ, Diyaolou OA, Hamed AA, Rateb ME, Ebel R. Egyptian fungal antibiotic metabolites-from pharaohs to modern textiles. Marine Drugs. 2020; 59-59.

22. Abdel-Aziz MS, Hathout AS, El-Neleety AA, Hamed AA, Sabry BA, Aly SE, Abdel Wahhab MA, Molecular identification of actinomycetes with antimicrobial, antioxidant and anticancer properties. Comun. Sci. 2019; 10: 218-231. 
23. Ingebrigtsen RA, Hansen E, Andersen JH, Eilertsen, HC. Light and temperature effects on bioactivity in diatoms. J. Appl. Phycol. 2016, 28, pp.939-950.

24. Christensen GD, Simpson WA, Younger JJ, Baddour LM, Barrett FF, Melton DM, Beachey EH. Adherence of coagulase-negative staphylococci to plastic tissue culture plates: a quantitative model for the adherence of staphylococci to medical devices. Journal of Clinical Microbiology .1985;22: 996-1006.

25. Hamed AA, Kabary H, Khedr M, Emam AN. Antibiofilm, antimicrobial and cytotoxic activity of extracellular green-synthesized silver nanoparticles by two marine-derived actinomycete- RSC Advances 2020; 10361-10367.

26. Ghareeb MA, Shoeb HA, Madkour HMF, Refahy LA, Mohamed MA, Saad AM. Antioxidant and cytotoxic activities of flavonoidal compounds from Gmelina arborea (Roxb.). Global Journal of Pharmacology. 2014; 8: 87-97.

27. Ghareeb MA, Saad AM, Abdou AM, Refahy LA, Ahmed WS. A new kaempferol glycoside with antioxidant activity from Chenopodium ambrosioides growing in Egypt. Oriental Journal of Chemistry. 2016; 32: 3053-3061.

28. Saad AM, Abdel-Aleem AH, Ghareeb MA, Hamed MM, Abdel-Aziz MS, Hadad AH. In vitro antioxidant, antimicrobial and cytotoxic activities and green biosynthesis of silver \& gold nanoparticles using Callistemon citrinus leaf extract. Journal of Applied Pharmaceutical Sciences. 2017;7: 141-149.

29. Shoeb HA, Madkour HMF, Refahy LA, Mohamed MA, Saad MA, Ghareeb MA. Antioxidant and cytotoxic activities of Gmelina arborea (ROXB.) leaves. British Journal of Pharmaceutical Research. 2014; 4: 125-144.

30. Kupchan SM. Recent advances in the chemistry of terpenoid tumor inhibitors. University of Wisconsin.1969.

31. Tan RX, Wolfender JL, Zhang LX, Ma WG, Fuzzati N, Marston A, Hostettmann K. Acyl secoiridoids and antifungal constituents from Gentiana macrophylla. Phytochemistry. 1996;42: 1305-1313.

32. MossmannT. Rapid colorimetric assay for cellular growth and survival: application to proliferation and cytotoxicity assays. J Immunol Meth. 1983; 65: 55-63.

33. Wilson AP. Cytotoxicity and viability assays. In JRW Masters, Animal Cell Culture, 3rd ed., Oxford University, Oxford. 2000; 175-219

34. El - Zayat SA, Nassar MSM, El-Hissy FT, Abdel-Motaal FF. Mycoflora associated with Hyoscyamus muticus growing under an extremely arid desert environment (Aswan region, Egypt). Journal of basic microbiology, 2008; 48:82-92.

35. Abdel-Motaal FF, Nassar MM, El-Zayat SA, El-Sayed MA, Ito S. Antifungal activity of endophytic fungi isolated from Egyptian henbane (Hyoscyamus muticus L.). Pakistan Journal of Botany. 2010; 42: 2883-2894

36. Sharma D, PramanikA, Agrawal PK. "Evaluation of bioactive secondary metabolites from endophytic fungus Pestalotiopsis neglecta BAB5510 isolated from leaves of Cupressus torulosa D.Don." 3 Biotech. 2016; 6: 210.

37. El-Said AHM, Shebany YM, Hussein MA, El-Dawy EGA. Antimicrobial and L-asparaginase activities of endophytic fungi isolated from Datura innoxia and Hyoscyamus muticus medicinal plants. European Journal of Biological Research. 2016.

38. Basheer MA, Mekawy AA, El Kafrawy SB, Abouzeid MA. Antimicrobial activities of endophytic fungi of Red Sea aquatic plant Avicennia marina. Egyptian Journal of Microbiology. 2018; 53: 0.

39. Gherbawy YA, Elhariry HM. Endophytic fungi associated with highaltitude Juniperus trees and their antimicrobial activities. Plant Biosystems. 2016; 150: 131-140.

40. Barbour EK, Sharif MA, Sagherian VK, Habre AN, Talhouk RS, Talhouk SN. Screening of selected indigenous plants of Lebanon for antimicrobial activity. Journal of Ethnopharmacology. 2004; 93: 1-7.
41. Ghareeb MA, Shoeb HA, Madkour HMF, Refahy LA, Mohamed MA, Saad AM. Radical scavenging potential and cytotoxic activity of phenolic compounds from Tectona grandis (Linn.). Global Journal of Pharmacology. 2013; 7: 486-497.

42. Hamed MM, Ghareeb MA, Shafei AA, Abdel-Aziz MS, Tolba SS. The in vitro evaluation of antioxidant, anticancer and antimicrobial properties of Araucaria heterophylla grown in Egypt. Pharmacologyonline. 2019; 1: $221-235$

43. Rudgers JA, Koslow JM, Clay K. Endophytic fungi alter relationships between diversity and ecosystem properties. Ecology Letters. 2004; pp 7: 42-51.

44. Ghareeb MA, Khalaf OM, Abdel-Aziz MS, Saad AM, Madkour HMF, ElZiaty AK, Refahy LA. Chemical profiles and bio-activities of different extracts of Terfezia species and their other associated fungi. Current Bioactive Compounds. .2019; 15(6): 1-11.

45. Ghareeb MA, Hamed MM, Saad AM, Abdel-Aziz MS, Hamed AA Refahy LA. Bioactive secondary metabolites from the locally isolated terrestrial fungus. Penicillium sp. SAM16-EGY. Pharmacogn. Res. 2019; 11: 162-170.

46. Martin-Rodriguez AJ, Reyes F, Martin J, Perez-Yepez J, Leon- Barrios $M$, Couttolenc $A$, et al. Inhibition of bacterial quorum sensing by extracts from aquatic fungi: first report from marine endophytes. Mar Drugs. 2014; 12:5503-5526.

47. Rajivgandhi G, Vijayan R, Maruthupandy M, Vaseeharan B, Manoharan N. Antibiofilm effect of Nocardiopsis sp. GRG 1 (KT235640) compound against biofilm forming Gram negative bacteria on UTIs. Microb Pathog. 2018 May;118:190-198. doi: 10.1016/j.micpath.2018.03.011. Epub 2018 Mar 7. PMID: 29524549

48. Meenambiga SS, Rajagopal K. Antibiofilm activity and molecular docking studies of bioactive secondary metabolites from endophytic fungus Aspergillus nidulans on oral Candida albicans. Journal of Applied Pharmaceutical Sciences.2018; 8: 037-045.

49. Kumar S, Stecher G, Tamura K. MEGA7: molecular evolutionary genetics analysis version 7.0 for bigger datasets. 2016; 33:1870-1874.

50. Bhatia R, Narain JP. The growing challenge of antimicrobial resistance in the South-East Asia Region-are we losing the battle? Indian Journal of Medical Research. 2010; 132: 482-486.

51. Morens DM, Folkers GK, Fauci AS. The challenge of emerging and reemerging infectious diseases. Nature. 2004; 430:242-249.

52. Jalgaonwala R, Mohite B, Mahajan RA. Review: natural products from plant associated endophytic fungi. Journal of Microbiology and Biotechnology Research. 2011; 1: 21-32.

53. Salvador-Reyes LA, Luesch $H$. Biological targets and mechanisms of action of natural products from marine cyanobacteria. Nat. Prod. Rep. 2015; 32: 478-503.

54. Stierle AA, Stierle D B. Bioactive secondary metabolites produced by the fungal endophytes of conifers. Natural Product Communications .2015; 10: 1671-1682.

55. Abd El-Hady FK, Shaker KH, Souleman AMA, Fayad W, Abdel-Aziz MS, Hamed AA, lodice C, Tommonaro G. Comparative Correlation Between Chemical Composition and Cytotoxic Potential of the CoralAssociated Fungus Aspergillus sp. 2C1-EGY Against Human Colon Cancer Cells Current microbiology.2017;1294-1300.

56. Kusari S, Lamshoft M, Spiteller M. Aspergillus fumigatus Fresenius, an endophytic fungus from Juniperus communis L. Horstmann as a novel source of the anticancer pro-drug deoxypodophyllotoxin. Journal of Applied Microbiology. 2009;107: 1019-1030.

57. Budhiraja A, Nepali K, Sapra S, Gupta S, Kumar S, Dhar K. Bioactive metabolites from an endophytic fungus of Aspergillus species isolated from seeds of Gloriosa superba Linn. Medicinal Chemistry Research. 2013; 22: 323-329.

58. Lee YM, Li H, Hong J, Cho HY, Bae KS, Kim MA, Kim DK, Jung JH. Bioactive metabolites from the sponge-derived fungus Aspergillus versicolor. Archives of Pharmacal Research .2010; 33: 231-235. 


\section{GRAPHICAL ABSTRACT}

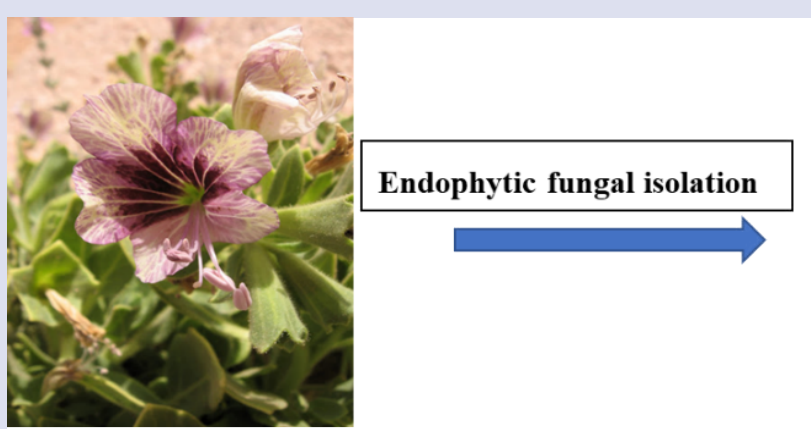

\section{Aspergillus \\ tubenginses}

\section{Hyoscyamus muticus}
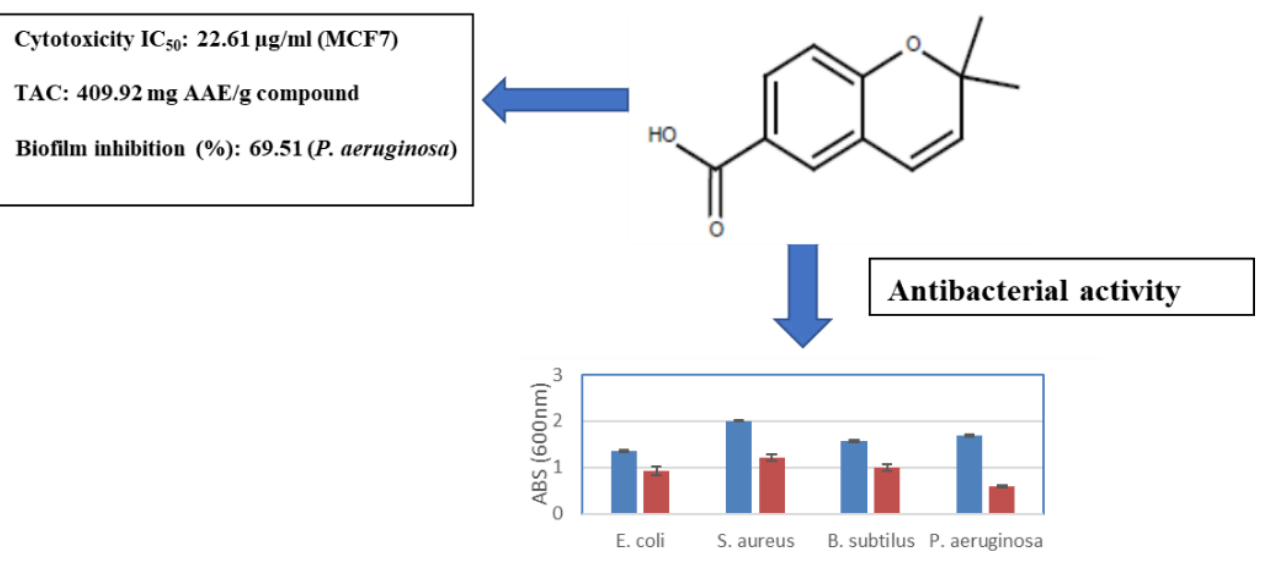

mblank = Anofinic acid

\section{ABOUT AUTHORS}

- Heba I. El-khouly assistant teacher of Microbiology, Botany and Microbiology Dept, Faculty of Science. Al-Azhar University (Girls Branch)

- Ass. Prof. Mosad Ahmed Ghareeb Ibrahim Associate Professor at Biochemistry \& Molecular Biology and Medicinal Chemistry Department, Theodor Bilharz Research Institute (TBRI), Giza, Egypt

- Ass. Prof. Asmaa M. El Hosainy Associate Professor of Microbiology, Botany and Microbiology Dept, Faculty of Science. Al-Azhar University (Girls Branch).

- Ass. Prof. Ahmed Abd Elghani Hamed Shalabi Associate Professor at Microbial Chemistry Department, Genetic engineering and biotechnology, National Research Centre, Egypt.

- Prof. Dr. Nagwa, M. Sidkey Prof. of Microbiology and Environmental Biotechnology. Botany and Microbiology Dept. Faculty of Science. Al-Azhar University (Girls Branch).

Cite this article: Elkhouly HI, Hamed AA, El Hosainy AM, Ghareeb MA, Sidkey NM. Bioactive Secondary Metabolite from Endophytic Aspergillus Tubenginses ASH4 Isolated from Hyoscyamus muticus: Antimicrobial, Antibiofilm, Antioxidant and Anticancer Activity. Pharmacog J. 2021;13(2): 434-42. 